\title{
Etiology and outcome of acute liver failure: Experience from a liver transplantation centre in Montreal
}

\author{
Geneviève Tessier MD, Edith Villeneuve MD, Jean-Pierre Villeneuve MD
}

G Tessier, E Villeneuve, J-P Villeneuve. Etiology and outcome of acute liver failure: Experience from a liver transplantation centre in Montreal. Can J Gastroenterol 2002;16(10):672-676.

BACKGROUND: Acute liver failure is a rare condition in which massive liver injury is associated with the rapid development of hepatic encephalopathy. Although viral hepatitis and drug-induced liver injury are the most common causes, no specific etiology is found in a substantial proportion of cases reported from Europe and the United States.

AIM: To determine the etiology and outcome of patients with acute liver failure in the authors' institution.

PATIENTS AND METHODS: The charts of 81 consecutive patients admitted to Saint-Luc between 1991 and 1999 were reviewed.

RESULTS: The etiology was viral in 27 cases (33.2\%), toxic or drug-induced in $22(27.2 \%)$, of unknown origin in $22(27.2 \%)$ and due to various causes in $10(12.3 \%)$ (autoimmune, vascular, cancer). Of the 81 patients, $16 \%$ survived without liver transplantation, and $84 \%$ died or underwent liver transplantation. Survival without liver transplantation differed according to the mode of presentation: the survival rate was $27 \%$ in patients with hyperacute liver failure, $7 \%$ in those with acute liver failure and $0 \%$ in those with subacute liver failure. Among the 38 patients who underwent liver transplantation, survival one year after transplantation was $71 \%$. In the 30 patients who died without liver transplantation, the main causes of death were cerebral edema and sepsis.

CONCLUSIONS: Acute liver failure is associated with a high mortality, and liver transplantation is the treatment of choice. In a significant proportion of cases, the etiology remains undeter- mined and is probably related to yet unidentified hepatotropic viruses.

Key Words: Acute liver failure; Fulminant hepatitis; Liver transplantation

Étiologie et pronostic de l'insuffisance hépatique aiguë : Expérience menée dans un centre de transplantation hépatique de Montréal

HISTORIQUE : L'insuffisance hépatique aiguë est un problème de santé rare, caractérisé par une atteinte massive du foie associée au développement rapide d'une encéphalopathie d'origine hépatique. Bien que l'hépatite virale et que l'atteinte hépatique d'origine médicamenteuse en soient les principales causes, aucune étiologie spécifique n’a été arrêtée dans une proportion importante de cas signalés en Europe et aux ÉtatsUnis.

BUT : Déterminer l'étiologie et l'évolution des cas d'insuffisance hépatique aiguë traités dans l'établissement des auteurs.

PATIENTS ET MÉTHODES : Les dossiers de 81 patients consécutifs admis à l'Hôpital Saint-Luc entre 1991 et 1999 ont été passés en revue. RÉSULTATS : L'étiologie s'est révélée virale dans 27 cas (33,2\%), toxique ou d'origine médicamenteuse dans 22 cas $(27,2 \%)$, d'origine inconnue dans 22 cas $(27,2 \%)$ et de causes diverses dans 10 cas (12,3\%) (cause auto-immune, vasculaire, ou cancer). Parmi les 81 patients, $16 \%$ ont survécu sans transplantation hépatique et $84 \%$ sont décédés et ont dû subir une transplantation hépatique. La survie sans transplantation hépatique a différé selon le mode de présentation. Le taux de survie a été de

suite à la page suivante

Division of Hepatology, Hôpital Saint-Luc, Centre Hospitalier de l'Université de Montréal, Montréal, Québec

Correspondence and reprints: Dr Jean-Pierre Villeneuve, Liver Unit, Centre de recherche du CHUM, Hôpital Saint-Luc, 264 East

René-Lévesque blvd, Montréal, Québec H2X 1P1. Telephone 514-890-8000 ext 35722, fax 514-412-7314, email villej@sympatico.ca

Received for publication May 17, 2001. Accepted August 8, 2002 
$27 \%$ chez les patients souffrant d'insuffisance hépatique hyperaiguë, de $7 \%$ chez les patients atteints d'insuffisance hépatique aiguë et de $0 \%$ chez les sujets atteints d'une insuffisance hépatique sub-aiguë. Parmi les 38 patients qui ont subi une transplantation du foie, la survie un an après la transplantation a été de $71 \%$. Chez les 30 patients décédés sans transplantation hépatique, les principales causes de mortalité ont été l'œè̀me cérébral et la septicémie.

CONCLUSIONS : L'insuffisance hépatique aiguë est associée à un fort taux de mortalité et la transplantation hépatique est le traitement de choix. Dans une proportion significative de cas, l'étiologie reste à déterminer et procède probablement de virus hépatotropiques pour l'instant non identifiés.

A cute liver failure is an uncommon but dramatic syndrome that is defined as an acute, often fatal illness that results from massive hepatic necrosis (1). The hepatic damage leads rapidly to encephalopathy, coagulopathy, cerebral edema and multiorgan failure. The prognosis is poor, with a mortality rate of about $80 \%$ without liver transplantation.

Recently, a few papers have described the epidemiology of acute liver failure. Most of the reports are from Europe and the United States (2-4). In the United States, the annual incidence of acute liver failure has been estimated to be approximately one in 100,000 (5). Applying this figure to Canada, about 300 cases would be expected to occur annually in Canada, and 70 cases in the province of Quebec. To our knowledge, large series of acute liver failure in Canada or Quebec have not been previously reported.

The aim of the present study was to describe the etiology and outcome of acute liver failure in a referral centre for liver disease in the Montreal area.

\section{PATIENTS AND METHODS}

Data were retrospectively collected on 81 patients admitted to Hôpital Saint-Luc with a diagnosis of acute liver failure, during a nine-year period from January 1, 1991 to December 31, 1999. Patients with known underlying liver disease were excluded from the study.

Acute liver failure was classified according to O'Grady et al (6). Hyperacute liver failure is defined as encephalopathy developing within seven days of the onset of jaundice. Acute liver failure is encephalopathy developing within eight to 28 days of the onset of jaundice, while in subacute liver failure, the encephalopathy occurs four to 26 weeks after the onset of jaundice.

During the study period, all patients with acute liver failure were admitted to a general intensive care unit. The severity of hepatic encephalopathy was divided into four grades (7). Intracranial pressure monitoring was not used routinely, but a subdural transducer was inserted in 11 patients during the study period. Hemocultures and cultures of all available fluids were performed routinely, but prophylactic administration of antibiotics was not used systematically. In patients eligible for liver transplantation, the decision to list them for transplantation was made by a medicosurgical team experienced in the care of these patients. In general, patients with hyperacute liver failure were listed when they developed grade IV hepatic encephalopathy and those with acute liver failure were listed when they developed grade III encephalopathy. Patients with subacute liver failure and without grade III or

\section{TABLE 1}

\section{Etiology of acute liver failure in 81 consecutive cases}

\begin{tabular}{lc}
\hline & $\mathbf{n}(\%)$ \\
\hline Viral hepatitis & $27(33.3)$ \\
Hepatitis A & 4 \\
Hepatitis B & 18 \\
Hepatitis B + D & 2 \\
Herpes simplex & 3 \\
Drugs and toxins & $22(27.2)$ \\
Acetaminophen & 12 \\
Isoniazide & 2 \\
Salazopyrine & 1 \\
Erythromycin & 1 \\
Azithromycin & 1 \\
Cyproterone & 1 \\
Naproxen & 1 \\
Germander & 1 \\
Amanita verosa & 1 \\
Carbon tetrachloride & 1 \\
Miscellaneous & $10(12.3)$ \\
Autoimmune hepatitis & 6 \\
Budd-Chiari & 2 \\
Heat stroke & 1 \\
Lymphoma & 1 \\
Cryptogenic & $22(27.2)$ \\
\hline
\end{tabular}

IV encephalopathy were also listed when no improvement was observed after a seven- to 10-day period of observation.

The outcome of patients with acute liver failure at the Hôpital Saint-Luc, Centre Hospitalier de l'Université de Montréal, Québec, was compared with that predicted by the prognostic model developed at King's College Hospital (7). According to this model, in patients with acetaminophen-induced acute liver failure, the presence of an arterial blood $\mathrm{pH}$ less than 7.30 or of hepatic encephalopathy grade III or IV with a serum creatinine greater than $300 \mu \mathrm{mol} / \mathrm{L}$ and an International Normalized Ratio (INR) higher than 6.5 predicts a high likelihood of death. In patients with nonacetaminophen-induced liver failure, a high likelihood of death is predicted by an INR higher than 6.5 , or the presence of any three of the following variables: age younger 


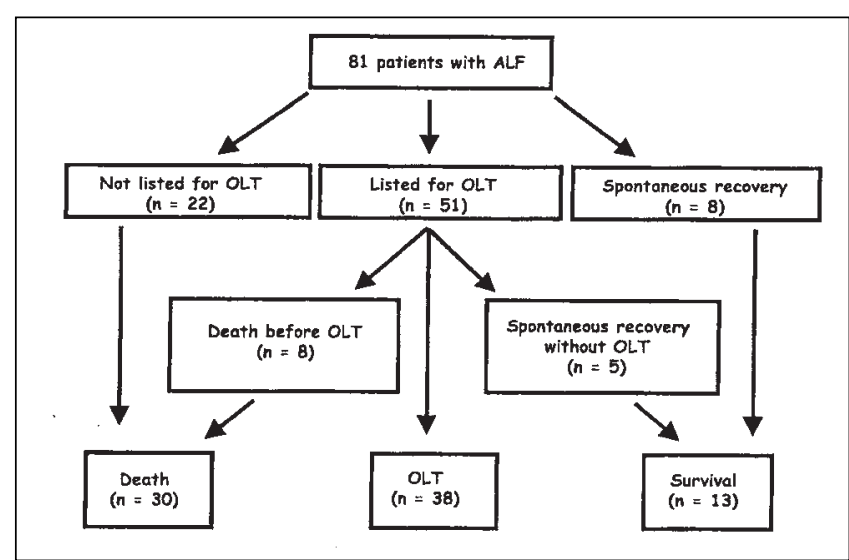

Figure 1) Outcomes of 81 patients with acute liver failure. ALF Acute liver failure; OLT Orthotopic liver transplantation

than 10 years or older than 40 years, acute or subacute liver failure, INR higher than 3.5, serum bilirubin concentration higher than $300 \mu \mathrm{mol} / \mathrm{L}$ and etiology due to non- $\mathrm{A}$, non-B hepatitis or idiosyncratic drug reactions.

\section{RESULTS}

The charts of 81 consecutive patients admitted to the Hôpital Saint-Luc, Centre Hospitalier de l'Université de Montréal, with a diagnosis of acute liver failure during a nine-year period were reviewed. There were 47 men and 34 women, and the mean age was 38.5 years. The etiology of fulminant hepatic failure is shown in Table 1. Overall, viral hepatitis was the most common cause (33.3\%), followed by cryptogenic $(27.2 \%)$ and drug- or toxin-induced liver injury $(27.2 \%)$. The miscellaneous category (12.3\%) included autoimmune hepatitis, Budd-Chiari syndrome, heat stroke and lymphoma. Among cases of viral hepatitis, hepatitis B was the most common etiology, whereas acetaminophen was the most common cause of drug-induced liver injury.

The outcomes of the 81 patients are shown in Figure 1. Fifty-one patients were listed for liver transplantation: 38 of them underwent liver transplantation after a median waiting time of two days (range zero to 22 days), eight patients died or developed contraindications to liver transplantation and died before a liver became available (median waiting time three days, range zero to nine days), and five patients improved spontaneously and were removed from the list. Thirty patients were not listed for liver transplantation: eight did not progress to grade III or IV encephalopathy and recovered spontaneously, and 22 had contraindications to liver transplantation. Thus, overall, $47 \%$ underwent liver transplantation, 16\% recovered spontaneously and 37\% died without transplantation.

For the 22 patients who died without being listed for transplantation, contraindications to liver transplantation were as follows: infection $(n=7)$, substance abuse $(n=5)$, psychiatric disease $(n=3)$, cancer $(n=2)$, refusal of liver transplant $(\mathrm{n}=1)$ and rapid death from complications of

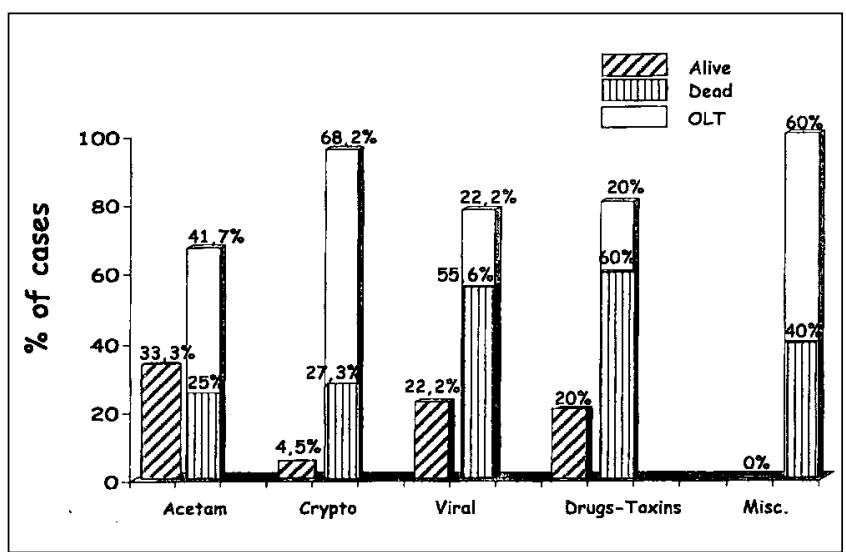

Figure 2) Outcomes of 81 patients with acute liver failure according to etiology. Acetam Acetaminophen; crypto Cryptogenic; Misc Miscellaneous; OLT Orthotopic liver transplantation

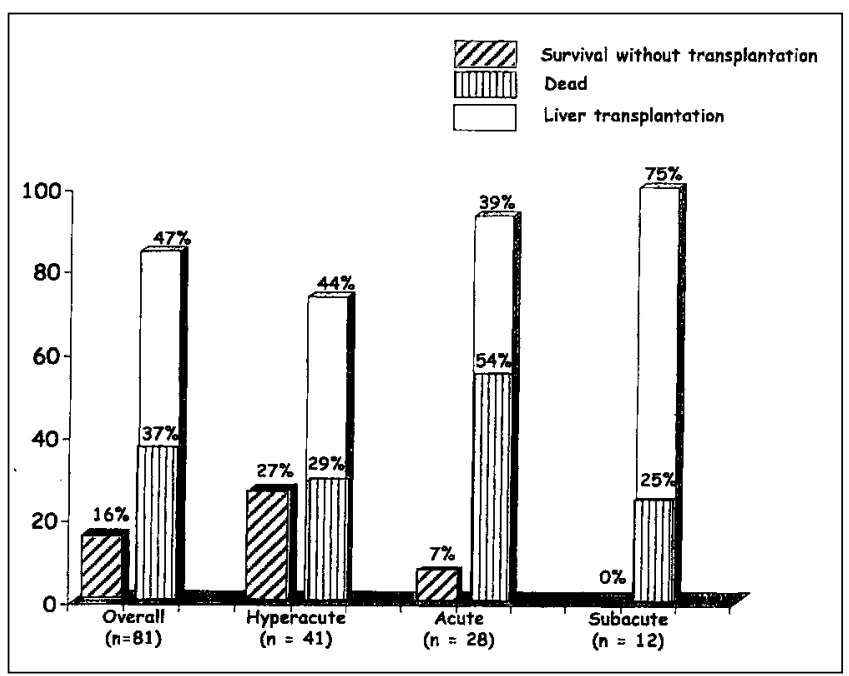

Figure 3) Outcomes of 81 patients with acute liver failure according to the mode of presentation

acute liver failure (one multiorgan failure, two massive bleeding and one cerebral edema).

The outcomes of patients according to the etiology of liver failure are shown in Figure 2. Acetaminophen was associated with the highest rate of survival without liver transplantation, whereas spontaneous survival was only $5 \%$ in patients with cryptogenic acute liver failure. The outcomes according to the mode of presentation (hyperacute, acute, subacute) are shown in Figure 3. The highest spontaneous survival rate was seen in patients with hyperacute liver failure, and the lowest in those with subacute liver failure.

In the 30 patients who did not receive a liver transplantation and died, liver failure with cerebral edema was the most common cause of death $(n=21)$, but sepsis was also an important cause of mortality $(n=5)$. Three patients died of bleeding secondary to severe coagulopathy, and one of multiorgan failure.

Among the 38 patients who underwent liver transplantation, $27(71 \%)$ survived and were alive at one year after 


\begin{tabular}{|c|c|c|c|c|}
\hline & \multicolumn{4}{|c|}{ Study, author (reference) } \\
\hline & O’Grady et al (7) & Pauwels et al (8) & Anand et al (9) & Present study \\
\hline \multicolumn{5}{|c|}{ Nonacetaminophen-induced liver failure } \\
\hline Number of cases & 54 & 81 & 25 & 36 \\
\hline Number of deaths (\%) & $44(81)$ & $66(81)$ & $18(72)$ & $27(75)$ \\
\hline Sensitivity (\%) & 91 & 79 & 72 & 79 \\
\hline Specificity (\%) & 90 & 86 & 43 & 55 \\
\hline Positive predictive value (\%) & 98 & 96 & 79 & 84 \\
\hline Negative predictive value (\%) & 82 & 50 & 50 & 45 \\
\hline Predictive accuracy (\%) & 94 & 80 & 68 & 73 \\
\hline \multicolumn{5}{|l|}{ Acetaminophen-induced liver failure } \\
\hline Number of cases & 121 & - & 120 & 7 \\
\hline Number of deaths (\%) & $43(36)$ & - & $48(40)$ & $3(43)$ \\
\hline Sensitivity (\%) & 72 & - & 90 & 100 \\
\hline Specificity (\%) & 92 & - & 83 & 75 \\
\hline Positive predictive value (\%) & 84 & - & 88 & 75 \\
\hline Negative predictive value (\%) & 86 & - & 65 & 100 \\
\hline Predictive accuracy (\%) & 85 & - & 71 & 86 \\
\hline
\end{tabular}

transplantation, whereas 11 (29\%) died. There was a trend for an improvement in the results of liver transplantation over time: during the 1991 to 1995 period, one-year survival was 59\% (10 of 17 cases), whereas in the 1996 to 1999 period, it increased to $76 \%$ (16 of 21 cases). The causes of death included sepsis $(n=6)$, cerebral edema $(n=1)$, acute liver rejection $(n=1)$ and cardiac failure $(n=1)$, whereas two patients with cryptogenic acute liver failure developed recurrent fulminant hepatitis in the transplanted liver, as confirmed by histology, and died. Eight of 38 patients who received transplants underwent a second liver transplantation because of hepatic artery thrombosis $(n=6)$, primary graft nonfunction $(n=1)$ or recurrent fulminant hepatitis $(n=1)$. Only three of eight survived.

To evaluate the validity of the King's criteria to predict outcome, patients who underwent liver transplantation were excluded from analysis, because the outcomes of these patients without transplantation could not be predicted with certainty. The King's criteria were present in 31 of 38 patients who underwent liver transplantation. Among the 43 patients who did not receive a transplant, 30 died and 13 survived. Among patients with nonacetaminophen-induced acute liver failure, the King's criteria were present in 21 of the 27 patients who died, and absent in five of the nine patients who survived. Thus, mortality was $84 \%$ when criteria were present (positive predictive value) and 55\% when criteria were absent (100 minus negative predictive value).

In patients with acetaminophen-induced acute liver failure, the King's criteria were present in the three patients who died, and absent in three of the four survivors. The predictive accuracy of the King's criteria is summarized in
Table 2, and compared with that reported in other publications. Overall, the predictive accuracy was similar to that reported by Pauwels et al (8) and Anand et al (9), but lower than that given in the original description of the model by O'Grady et al (7).

\section{DISCUSSION}

Acute liver failure is an uncommon disease, and few data are available on the etiology and outcome of this condition in Canada (10). In the present study, cryptogenic hepatitis was the most common cause of acute liver failure $(27 \%$ of cases), followed by hepatitis B (22\%) and acetaminophen overdose $(15 \%)$. The frequency of acetaminophen-induced acute liver failure in the present study is considerably less than that observed in the United Kingdom, where it accounts for $50 \%$ to $75 \%$ of all cases of acute liver failure $(3,11)$. By contrast, acetaminophen overdose only accounts for $2 \%$ of cases in France (2), whereas in the United States, a $20 \%$ frequency has been reported (4), similar to that of the present study.

Cryptogenic acute liver failure accounted for 27\% of cases in our study. A similar, although somewhat lower proportion, of cryptogenic cases (15\% to 20\%) has been reported in France, the United Kingdom and the United States (2-4). Evidence is accumulating to implicate yet unidentified hepatotropic viruses in cryptogenic acute liver failure (12). In a prospective study of British patients with cryptogenic acute liver failure, virus-like particles were detected in the cytoplasm of hepatocytes (13). In addition, after liver transplantation, liver failure recurred in some patients around seven days after grafting, with the appear- 
ance of the same virus-like particles in the graft (13). In the present study, acute liver failure recurred in the graft in two patients with cryptogenic fulminant hepatitis. In one of them, the disease recurred a second time after a second liver transplantation. Both patients died from disease recurrence. These observations provide support for the existence of yet unidentified transmissible agents in some cases of acute liver failure.

Spontaneous survival without liver transplantation was $16 \%$ in the present series, similar to the $25 \%$ figure reported by Schiodt et al (4). Acetaminophen overdose was associated with a relatively favourable outcome, whereas patients with cryptogenic liver failure had a poorer outcome. As reported by O'Grady et al (6), patients with acute or subacute liver failure had a much poorer prognosis than those with hyperacute liver failure. Among patients who died without liver transplantation, cerebral edema was the major cause of death, but sepsis also contributed to mortality. After liver transplantation, sepsis was also the major cause of death. Prophylactic systemic antibiotics reduce the risk of infection (14), but systematic cultures remain mandatory because early recognition of infection can be difficult in these patients.

The relatively high transplantation rate $(47 \%)$ in our series likely reflects a selection bias from a transplantation centre, because it is estimated that only $10 \%$ of patients with acute liver failure receive a liver graft in North America (5). Emergency liver transplantation has changed the outlook of acute liver failure, and the $71 \%$ one-year survival rate in the present series is comparable with that of others (10). The rate of retransplantation in the present study (eight of $38[21 \%]$ ) is higher than the $13 \%$ rate reported by Bismuth et al (15).

In patients with acute liver failure, early identification of those likely to die is essential so that liver transplantation can be done before complications such as cerebral edema, severe infection or multiorgan failure preclude the procedure. In 1989, O'Grady and colleagues (7) from the King's College Hospital in London, United Kingdom, proposed criteria for the early identification of patients having a high probability of death. The King's criteria are considered to be the best and most easily obtained criteria (15). In patients with acetaminophen-induced acute liver failure, the King's criteria are clearly useful: their positive predictive value for death is about $85 \%$, whereas the overall mortality ranges from $35 \%$ to $45 \%$. Our data, although in a very limited number of patients, support this view.

In patients with nonacetaminophen induced acute liver failure, the present data suggest that the King's criteria are less useful: their positive predictive value was only slightly higher than the overall mortality in this group. Their negative predictive value was low, indicating that a significant proportion of patients not selected by these criteria will not survive without liver transplantation. Thus, a strategy where patients with grade III or IV encephalopathy are listed for transplantation, as in our centre, probably yields results similar to one based on King's criteria (8,16-18).

\section{SUMMARY}

The present study indicates that the etiology and standard of care for acute hepatic failure in Montreal is similar to that observed in other North American and European centres. The high proportion of cases with cryptogenic acute liver failure stresses the need to search for new viruses. A Canadian registry, and a bank of liver tissue and serum in cases of fulminant hepatic failure would provide opportunities for research on the etiology and management of this rare and catastrophic condition.

\section{REFERENCES}

1. Mas A, Rodes J. Fulminant hepatic failure. Lancet 1997;349:1081-4.

2. Bernuau J, Rueff B, Benhamou JP. Fulminant and sub-fulminant liver failure: definition and causes. Semin Liver Dis 1986;6:97-106.

3. Tibbs C, Williams R. Viral causes and management of acute liver failure. J Hepatol 1995;22:S68-73.

4. Schiodt FV, Atillasoy E, Shakil O, et al. Etiology and outcome for 295 patients with acute liver failure in the United States. Liver Transplant Surg 1999;5:29-34.

5. Lee WM. Acute liver failure. N Engl J Med 1993;329:1862-72.

6. O'Grady JG, Schalm SW, Williams R. Acute liver failure: redefining the syndromes. Lancet 1993;342:273-5.

7. O'Grady JG, Alexander GJM, Hayllar KM, Williams R. Early indicators of prognosis in fulminant hepatic failure. Gastroenterology 1989;97:439-45.

8. Pauwels A, Mostafa-Kara N, Florent C, Levy VG. Emergency liver transplantation for acute liver failure. Evaluation of the London and Clichy criteria. J Hepatol 1993;17:124-7.

9. Anand AC, Nightingale P, Neuberger JM. Early indicators of prognosis in fulminant hepatic failure: an assessment of the King's criteria. J Hepatol 1997;26:62-8.

10. Wall WJ, Adams PC. Liver transplantation for fulminant hepatic failure: North American Experience. Liver Transplant Surg 1995;1:178-82.

11. Mutlmer DJ, Ayres RCS, Neuberger JM, et al. Serious paracetamol poisoning and the results of liver transplantation. Gut 1994;35:809-14.

12. Fagan EA. Acute liver failure of unknown pathogenesis: the hidden agenda. Hepatology 1994;19:1307-12.

13. Fagan EA, Ellis D, Tovey G, et al. Toga-like virus particles in fulminant sporadic non-A non-B hepatitis and after liver transplantation. J Med Virol 1992;38;71-7.

14. Rolando W, Philpott-Howard J, Williams R. Bacterial and fungal infection in acute liver failure. Semin Liver Dis 1996;16:389-402.

15. Bismuth H, Samuel D, Castaing D, Williams R, Pereira SP. Liver transplantation in Europe for patients with acute liver failure. Semin Liver Dis 1996;16:415-25.

16. Vickers C, Neuberger J, Buckels J, McMaster P, Elias E. Transplantation of the liver in adults and children with fulminant hepatic failure. J Hepatol 1988;7:143-50.

17. Brems JJ, Hiatt R, Ramming KP, Quinones-Baldrich WJ, Busuttil RW. Fulminant hepatic failure: the role of liver transplantation as primary therapy. Am J Surg 1987;154:137-40.

18. Castells A, Salmeron JM, Navasa M, et al. Liver transplantation for acute liver failure: analysis of applicability. Gastroenterology 1993;105:532-8. 


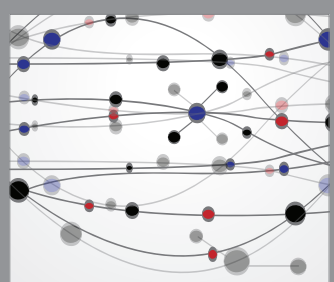

The Scientific World Journal
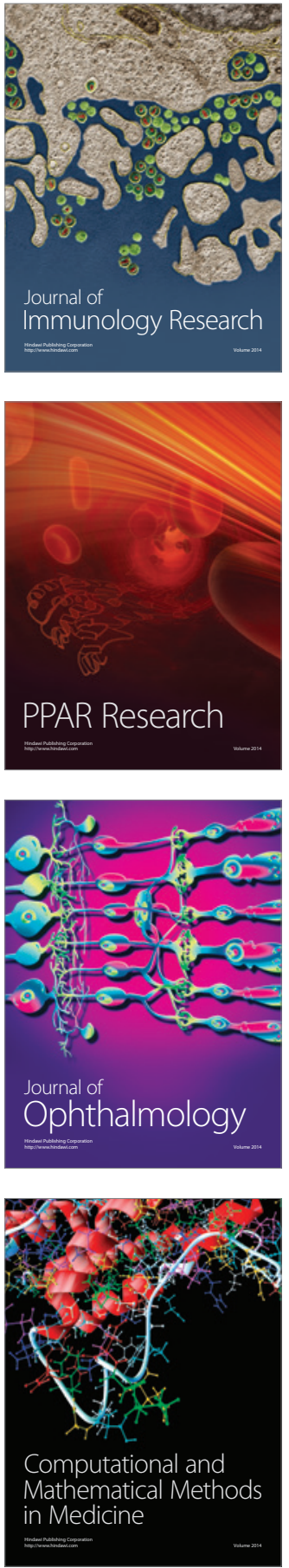

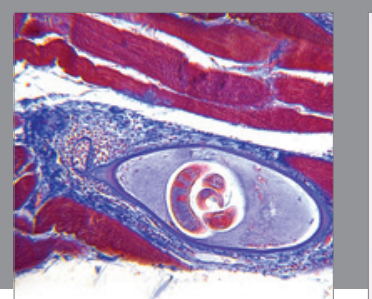

Gastroenterology Research and Practice

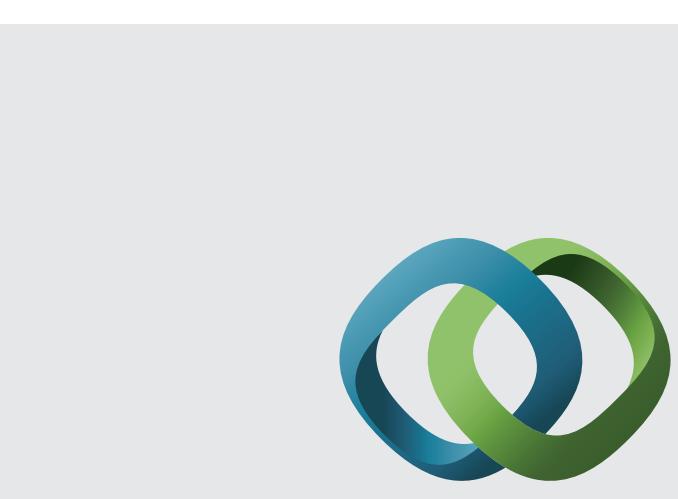

\section{Hindawi}

Submit your manuscripts at

http://www.hindawi.com
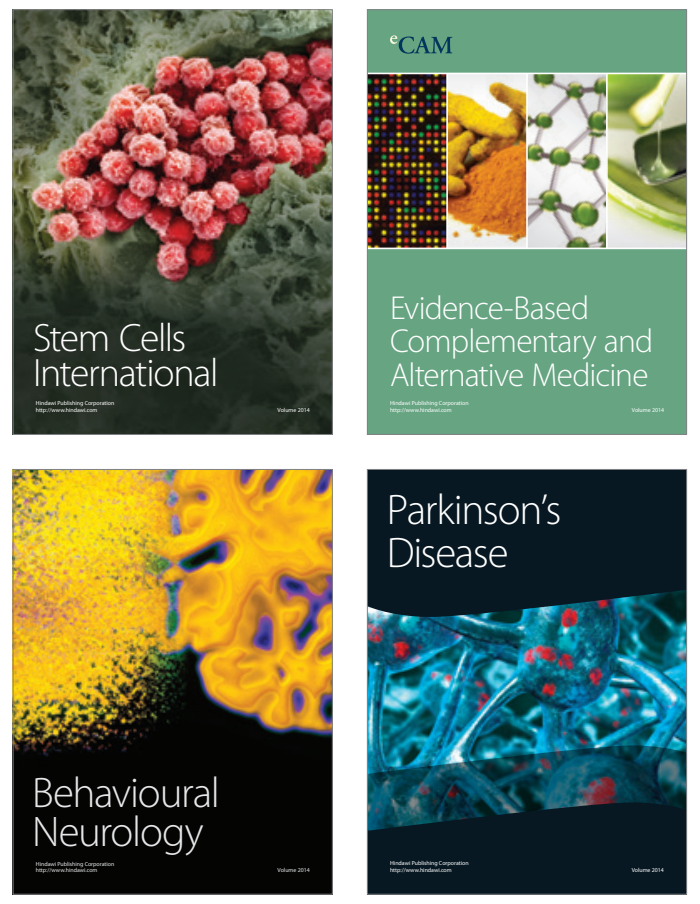
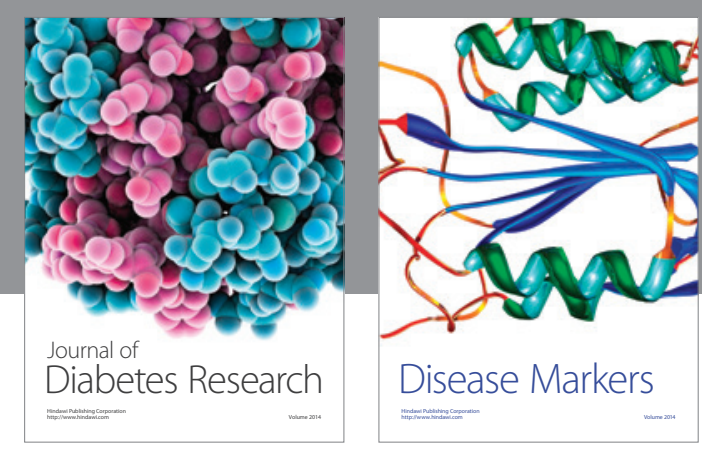

Disease Markers
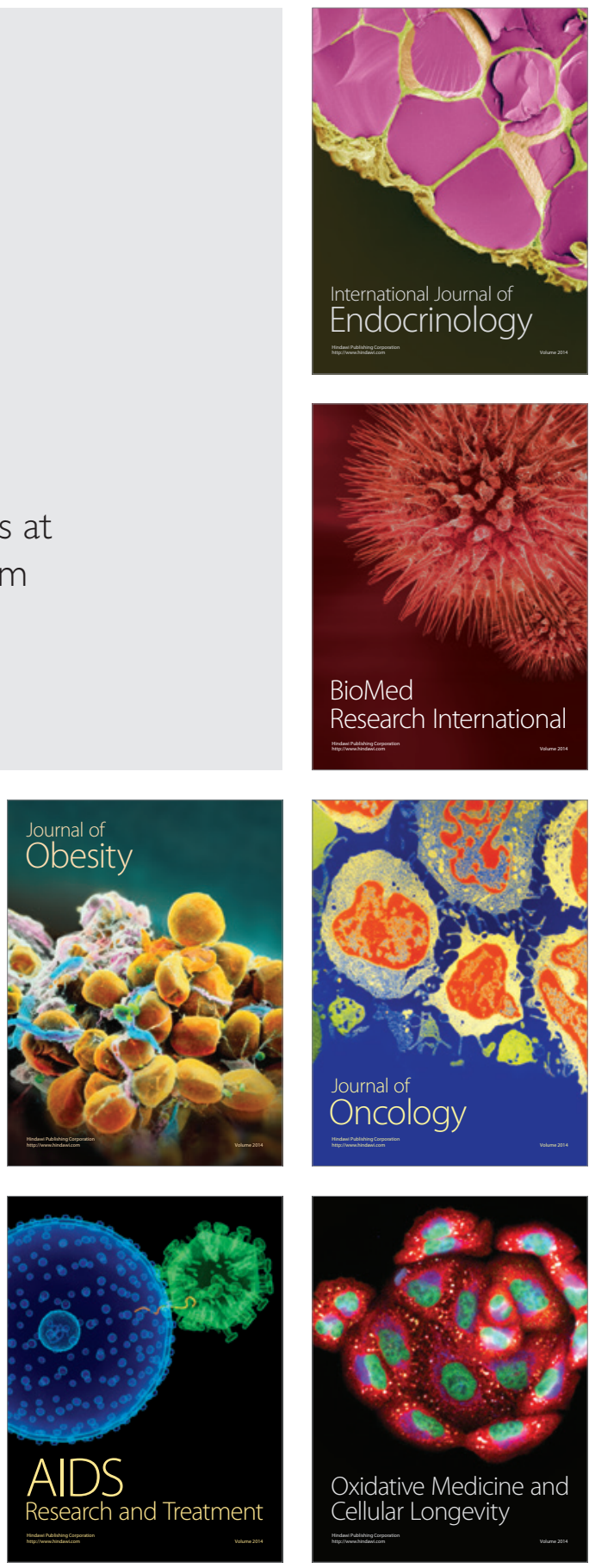